\title{
THE NATURE OF HYDROSALPINX.
}

By CLEMENT WHITE, M.D. (Cantab.).

The title "The Clinical History of Twenty Cases of Hydrosalpinx" perhaps would more nearly indicate the scope of this paper. Whatever conclusions are arrived at herein are drawn from notes taken at the bedside concerning the previous state of health, the present symptoms and physical signs of patients whose condition required cœliotomy and who were found to be the subjects of hydrosalpinx, the naked eye appearances of the diseased parts removed, and the character of the fluid contained in the diseased Fallopian tubes. It is from the standpoint of the previous life, and not of the microscopical details of the diseased parts, that the subject is approached. By this method I have endeavoured to find out what is the true pathological position of the condition known as hydrosalpinx. By what proves to be a coincidence the points gathered from the last six consecutive cases, four of which were under my own care as Resident Accoucheur at the London Hospital, are so remarkable that $I$ append them in a separate table. I can find no one who regards hydrosalpinx as due to a congenital malformation. The great majority of writers consider hydrosalpinx a product of salpingitis. To the kindness of Dr. Herman and Dr. Lewers $I$ owe it that I am permitted to make use of nineteen out of the twenty cases of my series. The twentieth was the case of a patient under the care of Mr. W. J. Robinson, of Old Brompton, Kent, who kindly allowed me to be present at the operation, and make use of the case. For the notes of this patient I am indebted to Mr. H. Cotman, House Surgeon of St. Bartholomew's Hospital, Rochester. Eighteen of the nineteen cases form a consecutive series comprising all the cases in which operation on patients in the gynæcological wards of the London Hospital revealed hydrosalpinx from 1893-1902, together with one case of hydrohæmatosalpinx in 1891, already published by Dr. Herman, in the Obstetrical Society's Transactions, Vol. xxxiii. The condition was barely recognised previous to this date, and abdominal operations were so much fewer that I did not think further search for cases in earlier years would repay the work involved. The yearly incidence of the cases was as follows:--

1902

1901

1900

1899

1898

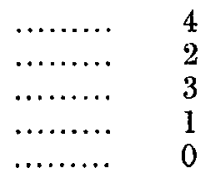

….... 0
1897

1896

1895

1894

1893

$\begin{array}{ll}\ldots \ldots \ldots & 4 \\ \ldots \ldots \ldots & \mathbf{2} \\ \ldots \ldots \ldots & 2 \\ \ldots \ldots \ldots & 0 \\ \ldots \ldots \ldots & 0\end{array}$


There are some twenty-eight beds in this department at the London Hospital constantly full of gynæcological cases, so that the rarity of the condition is evident. For the sake of comparison, it was to be noted that in 1901 and 1902, up to August, there were 19 cases of pyosalpinx revealed by operation and 59 cases of inflamed thickened appendages.

There is little space in the gynæcological text-books in general use devoted to hydrosalpinx. Didactic purposes and analogy are responsible for the category into which I imagine many men place hydrosalpinx. Useful though it may be for dogmatic teaching, analogy is proverbially fallacious. Personally-and I do not know that my experience was exceptional-the first impression on the subject which I received from teachers and text-books was that hydrosalpinx and a simple pleural effusion were analogous conditions. When a student is being introduced to the diseases of the Fallopian tubes, he has probably gained some experience in the medical wards of a hospital, and has learnt to classify diseases of the pleura under the heads of dry pleurisy, pleurisy with thickening of the pleura, and pleurisy with simple, purulent, or hæmorrhagic effusion. His memory may be aided if he is taught that there are similarly in the case of Fallopian tubes a catarrhal salpingitis, inflamed tube with thickening without dilatation, and inflamed tube with dilatation containing clear fluid (hydrosalpinx), or containing pus (pyosalpinx), or containing blood (hæmatosalpinx).

Such, as far as my recollection serves, is the way $I$ was led to consider the subject. That in very many cases this aspect is far from the truth I hope to show.

I will frankly state that though the previous history of the subjects of the disease and to some extent the naked eye appearances of the diseased parts removed convince me that hydrosalpinx is not invariably the result of inflammation of the tube, in a few cases it seems to be so. My opinion is that there are two, or possibly three, separate conditions which lead to hydrosalpinx.

What is the nature of the fluid contained in a hydrosalpinx, if it is not an inflammatory effusion, and what is its origin and process of secretion? I will here refer to one reported case-case six of a series of fifteen collected from the post-mortem room by Dr. Fowler, of Middlesex Hospital, which is the only one $I$ find in which the fluid distending the Fallopian tubes appeared to be secreted by the lining of those tubes while sharing in a general process of æedema. In this case the fimbrix of the left tube were adherent to the ovary, and of the right to the peritoneum; the tubes were distended with a 
glairy greyish coloured fluid. The patient had died of chronic interstitial nephritis, and other complications were pulmonary œdema, pericarditis, pleurisy, and œdema glottidis.

In this case the secretion in the Fallopian tubes was similar to the passive secretion of pleural effusion in late stages of kidney disease, producing the condition of hydrothorax. It is comparable to a hydropericardium rather than to a pericarditis with effusion, to an ascites without peritonitis rather than a peritonitis with ascites. But in the majority of cases I do not think the truth lies here.

Definition. By hydrosalpinx I means a Fallopian tube, with its abdominal ostium impervious, distended by non-purulent, nonhæmorrhagic fluid. It may be clear serous fluid of light amber colour, or may be darker coloured. I exclude an inflamed tube without any well-marked dilatation, containing serous fluid in small quantity, due merely to a catarrh of the mucous membrane of the Fallopian tube, a part of a general salpingitis by which the outer coats of the tube also are affected and thickened. Where can we find a similar condition in some other organ, for we need not consider the Fallopian tube to be subject to a diseased condition entirely peculiar to itself?

Turning to hydronephrosis, possibilities of comparison suggest themselves. Prominently at the outset we are met by a great and important difference-the kidney is an excretory organ, and the Fallopian tube is not. The Fallopian tube and the ovary together, when the fimbriated end of the tube embraces the ovary, are more comparable to the ureter and kidney. Still the ovary merely secretes, while the kidney excretes. There are points, however, of considerable resemblance, and the case of $\mathrm{M}$. $\mathrm{H}$. (case 5) may help to elucidate them, and be itself elucidated by the comparison. In the case mentioned a woman of 22 , married two and a half years, had no children and no miscarriages; she had pain for two years, had only menstruated for one and a half years, and that scantily. This was followed by eleven months' amenorrhœa, and dyschezia and dyspareunia for a few months. She had never been laid up in bed by previous inflammatory attacks. Her uterus was undersized, and somewhat retroverted. On the abdomen being opened the left tube was found dilated at its ampullary end to the size of a pigeon's egg, while its proximal end and the whole of the right tube felt very hard. On removal of the tubes from the body yellowish white calcareous bodies were found in their lumina. On the right side they were much more numerous, and appeared to block the tube completely. These bodies were rough, hard, and varying in size from a pin's head 
to a small pea, and at once suggested calculi. They were undoubtedly the most striking feature in a case where faulty development of the generative organs was evident. The possibility presented itself that these calcareous bodies in the left tube had intermittently blocked the lumen of the tube, that fluid secreted by the cells lining the Fallopian tube, altered doubtless, but not inflammatory, had collected behind the calcareous bodies, and caused dilatation of the tube, whose ostium (if ever pervious) became closed by adhesive peritonitis in the neighbourhood secondary to the diseased condition of the tube. On the right side there was little, if any, dilatation of the tube; the ostium was closed.

Turning to the kidney, we know that when the lumen of the ureter is completely occluded by ligature or stone, the condition of hydronephrosis is not produced. This fact suggests a reason why there was not a hydrosalpinx on the right side, the lumen of the right tube being completely blocked. But if the pelvis of the kidney contain a stone which intermittently blocks the mouth of the ureter while allowing an intermittent flow from the kidney, the conditions are present which favour the production of a hydronephrosis. Similar conditions were present in the left Fallopian tube in case 5, and intermittent blocking of the oviduct resulted in hydrosalpinx. The presence of calcareous bodies in Fallopian tubes recalls the fact that the oviducts of birds normally secrete eggshells. The association of calculi with hydrosalpinx is extremely rare.

Turning to the generality of cases of hydrosalpinx, we must look for some cause of temporary occlusion of the proximal ends of the Fallopian tubes apart from calculi. That which readily suggests itself is periodic occlusion of the lumen by congestion of the mucous membrane of the Fallopian tubes in connection with the menstrual cycle. It is not unreasonable to suppose that the mucous membrane of the Fallopian tubes shares the general pelvic congestion which occurs every month in women of child-bearing age. This congestion, coupled with faulty development, will give us the conditions necessary for the production of a hydrosalpinx; a survey of case 6 , which follows later, simplifies this point. A comparison then holds between, on the one hand, occlusion of the ureter by kinking and congestion, a condition rare in ocmparison with occlusion by renal calculus, and, on the other hand, occlusion of the Fallopian tube by congestion--infinitely more common than occlusion by stone. This is further comparable to the occlusion of the male urethra, in cases known as congestive stricture, in which congestion of its mucous membrane causes retention of urine. In the Fallopian tube 
this blocking by congestion is aided by the folds in its mucous membrane, its sinuous course and its lax attachments.

It is from the point of view of the blocking of the tube and as showing the reason why the fluid contained in a hydrosalpinx does not except intermittently, escape into and through the uterine cavity that the analogy of the renal apparatus is helpful. The analogy holds further in that the organ in each case, kidney and tube, becomes altered, till finally each is a thin-walled cyst, and has lost its original structure completely. But the analogy does not hold as to the origin and nature of the fluid; for this we must look elsewhere.

The common hydrocele in the male is a collection of fluid in what should be an obliterated portion of the peritoneum. Its cause is unknown. There is admittedly no relation of cause and effect between an acute and a chronic vaginal hydrocele. They are in a different category. So I believe are pyosalpinx and the vast majority of cases of hydrosalpinx in different categories, as far as their origin is concerned. I believe-and some cases of my series distinctly support the view--that a hydrosalpinx may become infected and become converted into a pyosalpinx. That the opposite sequence occurs I can find no evidence. To this point I revert later. . In a common hydrocele the cells lining it transude an abnormal fluid. I bcliere that in a hydrosalpinx the cells secrete an abnormal fluid, and afterwards the cyst wall, when the original cells are gone, transudes fluid. When the abdominal ostium is closed the oviduct has lost its proper function, and it is a matter of frequent observation that, when such loss of function occurs, cells do secrete abnormal fluid. This accounts for the various kinds of fluid observed in hydrosalpinges. Retention cysts in the breast, tubulodermoids, hydroceles of the canal of Nuck, hydroceles of the spermatic cord are all the outcome of developmental errors. Cystic degeneration of the ovaries, cysts of Kobelt's tubes or of the hydatid of Morgagni often exist side by side with hydrosalpinx. As in hydrops folliculi, there is a perversion of the secretion of the Graafian follicles, carried possibly to a greater extent in Rokitansky's ovarian tumours and multilocular ovarian cysts, so in hydrosalpinx is there perverted secretion of the lining of the Fallopian tube, rather than an inflammation.

Hydrosalpinx thus takes its place rather among teratoid tumours of the Fallopian tube than inflammations. Like other teratoid tumours, it is itself subject to inflammation and suppuration. Thus 
there is no difficulty in believing that a hydrosalpinx may become a hæmatosalpinx by hæmorrhage from the inflamed wall taking place into it-this seems to have occurred in a patient of Dr. Herman's, recently under my care, suffering from pyosalpinx on the one side and hæmatosalpinx on the other,- and pyogenic organisms may enter it and convert it into a pyosalpinx. Two cases of my series show tubo-ovarian abscesses, which, in my opinion, were tubo-ovarian cysts, which subsequently become infected by micro-organisms.

Granted that hydrosalpinx is a tumour, a retention cyst, in its growth it may, like any other tumour in the abdomen, set up peritonitis in the neighbourhood by pressure. 'This will account for the adhesions so often found in cases of hydrosalpinx. It has been customary when peritonitic adhesions were present in cases of hydrosalpinx to conclude at once that the peritonitis aided the occlusion of the tube; in fact, to say that the tumour was due to pelvic inflammation. But we do not say that an ovarian tumour is due to the adhesions which often surround it. Keeping this point in mind, the presence of old adhesions in cases of hydrosalpinx becomes, from an retiological point of view, relatively unimportant.

A consideration of case 6 falls in aptly here :-

A woman, aged 35 , married 15 years, had had no children and no miscarriages; she had generally enjoyed good health, had had no serious illness before that leading to her admission to hospital. Menstruation had been always scanty, fairly regular, with occasional pain. She suddenly developed symptoms of acute pelvic peritonitis. Examination revealed an abdominal tumour, diagnosed as an ovarian cyst, and operation a left suppurating tubo-ovarian cyst with recent peritonitis and right hydrosalpinx. I contend that the hydrosalpinx and the other developmental errors were a sufficient cause of her sterility, and that there was no evidence of inflammation previous to the illness during which she was operated upon.

In the light of the patient's history my interpretation of the condition found is as follows:-Both tubes were thickened in part of their course, the seat of a hyperplasia, which was apparently partly of long standing, possibly congenital, and partly due to recent inflammation. The ampullary portion of the right tube was dilated and the wall thinned measuring $2 \mathrm{in}$. by $1 \mathrm{in}$. in diameter; it contained thin clear fluid. The narrower isthmus and interstitial portion of the right tube, which were thickened, would be liable to become blocked at each monthly period by congestion of the mucous membrane. The secretion from the ampullary portion would then not be able to make its way into the isthmus, and would distend the outer portion of the tube. The fimbriated end either was congenitally impervious, or it would be embracing the ovary perhaps at the time of menstruation, or occluded by congestion of the fimbriæ leading to so-called "salpingitic" closure of the ostium or by adhesive peritonitis set up by the tubal secretion irritating the peritoneum. If it could be proved by post-mortem examinations of the Fallopian tubes in young girls that such 
congenital atresia of the abdominal ostium did exist, the alternative methods suggested by which the ostium becomes occluded might, in reference to this case, be dispensed with.

On the left side, besides distension of the tube, cystic change had occurred in the ovary. There was some dilatation of the ampullary end of the left Fallopian tube, which had become adherent to the ovary. The partition between the dilated tube and the ovary had become gradually thinned until the ovarian cyst and tube communicated. Then there was a cyst reaching to the level of the umbilicus in direct communication with the lumen of the isthmus of the Fallopian tube and uterine cavity. The next step was entrance of pyogenic organisms, suppuration in the tuboovarian cyst, and pelvic peritonitis. This occurred less than three weeks prior to operative interference. The fluid in the tubo-ovarian cyst was originally altered secretion of altered Graafian follicles and cells lining the Fallopian tube, not the result of inflammation. The entrance of pyogenic organisms was a pure accident, an epiphenomenon, and so was the pelvic peritonitis. The fluid which escaped from the cyst, which ruptured prior to removal, was dirty brown pus and blood, and contained gas. That it was fairly virulent was shown by the fact that the patient had suppuration in the pelvis afterwards. The stages then seem to have been as follows:--Developmental error in the proximal portion of both tubes, accumulation of fluid in the ampullary portions with closure of both abdominal ostia, and the formation of a cyst in the right ovary. At this stage there would be a double hydrosalpinx and right ovarian cyst. The next stage is left hydrosalpinx and right tubo-ovarian cyst. The last stage is suppuration in left tubo-ovarian cyst. In other words, here is a case of a tumour composed of right hydrosalpinx and ovarian cyst becoming right pyosalpinx and ovarian abscess.

I will add two views of the case which might be upheld by some. It might be said that the left hydrosalpinx had been a pyosalpinx, and the pus had become inspissated. If this had been so we should have expected the walls of the hydrosalpinx to be thick; they were not. Moreover those who believe in the existence of this process allow that it takes a long time. The time of actual illness was less than three weeks. The second view is that the left hydrosalpinx was consequent on the suppuration of the right tubo-ovarian cyst. I do not know whether the hydrosalpinx could have thus formed in three weeks. I do not think it probable. Nor do I see why the two tubal cysts should be considered to have had different modes of origin. I think congenital malformation of both tubes most simply accounts for the facts of the case. Most, if not all, would agree that the part the ovary played in the right-sided swelling was primarily neoplastic and subsequently inflammatory. Why should not the same be said of the left tube? Mr. Bland-Sutton holds that in tubo-ovarian swellings the mischief actually starts in the tube.

I cannot deny that the naked eye appearance of the undilated portions of the tubes was such as occurs in a pachysalpingitis, but the condition could, I think, have been the result of the few weeks' terminal pelvic peritonitis affecting ill-developed tubes.

In summarising the case the points $I$ would emphasise are:-

1. The patient was sterile.

2. There was enough disease of the generative organs to account for sterility.

3. If the condition of her generative organs caused her sterility, that condition must have been of long standing, some 15 years. 
4. There is no history of previous severe illness.

5. A neoplastic origin of hydrosalpinx accounts for these facts.

6. The case affords practically an example of hydrosalpinx being converted into a pyosalpinx.

The question has been raised by Zahn in an article on tubo-ovarian cysts in Virchow's Archiv, 1898, Band cli., supplement, whether hydrosalpinges are not always stages in the formation of tubo-ovarian cysts. I have examined my cases from this point of view, and while in some of them the ovary was closely adherent to the hydrosalpinx, it was not always so. Nor is there uniformly any disease to be found in the ovaries, though they frequently are cystic. It may be that in this case 6 the left ovary and tube were, owing to abnormal development, never separated off from one another in the way in which the normal ovary and tube become separated, and the adhesions between the ovary and tube then are not the result of inflammation at all, but of faulty development.

The following facts concerning the six cases of hydrosalpinx operated on in the London Hospital gynæcological theatres between January 1st, 1901, and July 31st, 1902, are important. (Cases 1 to 6 of this series) :-

1. All the patients were married, one twice.

2. All were absolutely sterile.

3. Average duration of married life 10.8 years.

4. Ages $22-4 \tilde{5}$.

5. In none could a history suggesting gonorrhcea be obtained.

6. In only one could any history of previous illness of an inflammatory type be obtained-viz., "rheumatic fever" without joint affections.

7. In five out of six cases there was no evidence or history of syphilis.

8. There were no tubercles visible to the naked eye in any of the diseased parts removed.

9. In five out of six cases there was disease of other portions of the genital apparatus, generally cystic disease of ovaries in varying degrees.

10. Symptoms. Case six had none referable to hydrosalpinx except scanty menstruation, sometimes with pain. Case 3 had none except possibly dysmenorrhœa. Cases 1, 2, and 5 had pain, severe and for many years. Case 4 had no symptoms of any severity till approach of menopause, when she had local peritonitis.

11. In no case is there any evidence that the hydrosalpinx was a sequel of pelvic peritonitis; whenever there was pelvic peritonitis it appears to have been consequent on the dilatation of the tube or due to other pelvic disease.

12. There was in no case evidence of hydrosalpinx having been previously pyosalpinx. The walls of the dilated portions were all thin.

Conclusion. The frequent absence of history of previous inflammation, though carefully inquired for, coupled with the fact of sterility, lead to the suggestion that the condition of hydrosalpinx is due to a developmental error, and is not in any true sense due to an inflammatory change. 
I now propose to consider seriatim and in partly tabular form, the following points :-

1. The age of the patients.

2. Their condition as to marriage, pregnancy, and labour.

3. History of previous inflammation.

4. Occurrence of other abnormal conditions in the pelvis side by side with hydrosalpinx.

5. Probable cause of hydrosalpinx in each case.

6. Symptoms.

7. Conclusions.

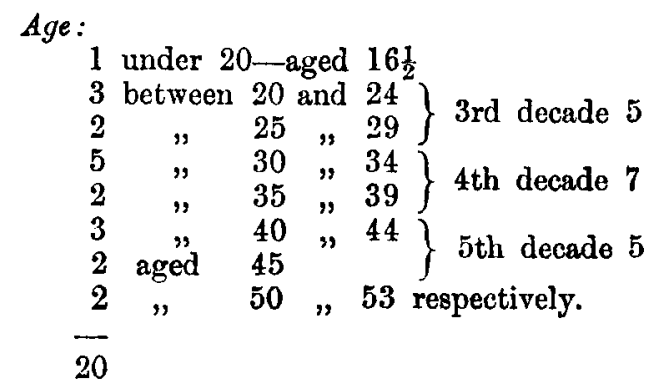

Single 2 Married 18.

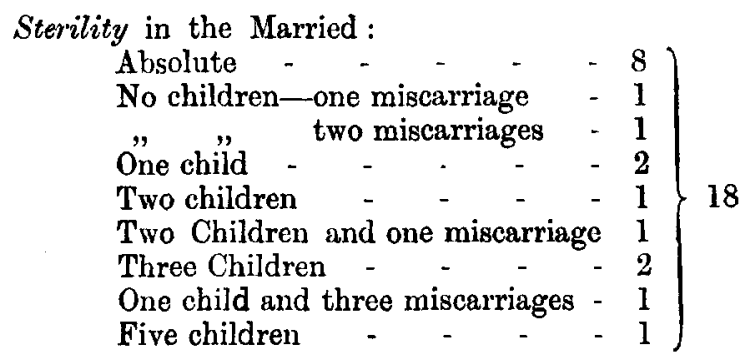

Thus out of the 20 patients 50 per cent. were never pregnant, the remaining ten became pregnant on 25 occasions altogether.

The number of years of married life of the absolutely sterile taken together was 86 years. In only two cases was the operation performed within less than seven years of marriage, and in those two the condition at the operation showed there was no chance of the patients ever having become pregnant. The average number of years of married life in the sterile was nearly 11 . Of 9 out of the 10 who were parous (omitting case 12 as doubtful and past the menopause) the total number of years of married was 129, giving an average of 14, while in these 9 cases the years of absolute sterility preceding operation were 85 , or averaged over 9 years. If the duration of sterility corresponds in any way with the life history of 
hydrosalpinx, we may conclude that in most cases of my series the hydrosalpinx had existed on an average for some 10 years before it was removed by operation.

History of Inflammation immediately following Pregnancy. Certainly in two cases, possibly in two other cases there was puerperal inflammation, in six there was none.

Was there any History pointing to Gonorrhoeal Infection in the Parous 10? In one case out of 10 the answer is positive, in two doubtful, in seven negative. Thus in three cases there was definite evidence of puerperal or gonorrhoeal inflammation, in three others it is doubtful, in one of these the balance of evidence being against gonorrhoea, while in the remaining four there is absolutely no evidence in favour of it. That is, in nearly half of the cases of hydrosalpinx occurring in parous women there is no evidence of gonorrhceal or puerperal inflammation.

History of Gonorrhoal Infection in the Nulliparous. In seven out of 10 there is no evidence whatever pointing to gonorrhoea, in the other three it is doubtful. Putting the 20 cases together, and putting cases where there is any reasonable doubt into the scale of " inflammation," yet 11 out of 20 , or more than half, have no history pointing to either gonorrhoal or puerperal pelvic inflammation. If any reliance can be placed upon clinical history, more than half the cases of hydrosalpinx cannot be stages of salpingitis due to gonorrhoea or following on pregnancy.

Occurrence of Recognised Developmental Errors and other Abnormalities side by side with Hydrosalpinx. CASE.

1. Both ovaries enlarged and cystic, right hydrosalpinx, old slight peritonitis.

2. Left ovary cystic, right suppurating tubo-ovarian cyst, left hydrosalpinx.

3. Right broad-ligament cyst (ovarian), left hydrosalpinx.

4. Calcareous deposits in both tubes, cystic right ovary, uterus small, left hydrosalpinx.

6. Left suppurating tubo-ovarian cyst, recent acute peritonitis, right hydrosalpinx.

7. Right cyst of Koblet's tube, left cystic ovary, double hydrosalpinx, dense adhesions, small uterine fibroids.

8. Right pyosalpinx and left hydrosalpinx.

9. Double hydrosalpinx. Dense adhesions.

10. Right hydrosalpinx, left ovary and tube inflamed.

11. Large sub-peritoneal uterine fibroid, peritoneal adhesions, left hydrosalpinx.

12. Left multilocular ovarian cyst, retroverted uterus, no adhesions, right hydrosalpinx.

13. Left ovarian cyst (simple), right cystic ovary and hydrosalpinx, old adhesions. 
14. Left ovarian cyst, right hydrosalpinx, extrauterine fotation.

15. Cyst of right side of vulva previously removed, double hydrosalpinx.

16. Right hydrosalpinx, some adhesions.

17. Double hydrosalpinx.

18. Right hydrosalpinx, slight peritoneal adhesions.

19. Left hydrosalpinx.

20. Hypertrophic elongation of cervix, left hydrohæmatosalpinx.

What is the bearing of this table on the question of the origin of hydrosalpinx. Three main possibilities present themselves.

1. The hydrosalpinx was a developmental error as much as were the other developmental errors, such as ovarian cysts.

2. The hydrosalpinx was an accident secondary to the other diseased conditions.

3. The hydrosalpinx was merely a stage of an inflammed tube.

With regard to the second view, I will quote the opening words of Dr. Cullingworth's "Diseases of the Fallopian Tubes":"Hydrosalpinx. The Fallopian tube in this affection becomes occluded at its fimbriated end, usually from a localised peritonitis originating in disease of some other part of the pelvis, not unfrequently in purulent inflammations of the tube on the opposite side. The closed tube subsequently becomes distended with serum, thus forming a retention cyst. The tube itself being as a rule otherwise free from disease, its walls become stretched and attenuated, the folds of the mucous membrane more or less obliterated, and the muscular coat atrophied." In three of the above cases there was purulent inflammation of the tube on the opposite side.

I will proceed to try and sift the evidence on these points in connection with the clinical history of each patient:-

CAsE 1. Both abdominal ostia were closed. There was hydrosalpinx on one side only. Hence something further than mere closing of the abdominal ostium is necessary for the production of a hydrosalpinx. (Bearing on this point, I remember a case of tubal abortion operated on last year in the London Hospital for internal bleeding from the right tube, in which the left ostium was closed, but there was no hydrosalpinx). Both ostia cannot have been closed prior to conception, $6 \frac{1}{2}$ years previous to operation. The ostia were apparently closed by peritonitic adhesions. The patient's chief symptom, pain on the right side, was of 15 years' duration, possibly due to right hydrosalpinx. The presence of this tumour complicating delivery might be enough to cause slight peritonitis, which closed the ostium of the opposite tube after delivery. There was a history of gastric ulcer and hæmatemesis.

CASn 2. The left hydrosalpinx may have been secondary to the right tubo-ovarian cyst. It may equally well have been a co-temporaneous or even prior developmental error. There was dysmenorrhoea for eight year's. There were acute symptoms due to the occurrence of inflammation and suppuration in the right tubo-ovarian cyst for 12 months. There were 
nine years' sterility. This is only partially accounted for by a one-sided lesion, but completely if the hydrosalpinx was of long standing. The tubo-ovarian cyst was practically a primary hydrosalpinx and an ovarian cyst. Symptoms dated from a fall eight years before operation.

CASE 3. There was a right-sided broad ligament cyst, apparently arising from the oophoron, and left hydrosalpinx. There was no history or sign of previous peritonitis. If closure of the ostium on the left side was due to pelvic peritonitis, of which the evidence had disappeared, set up by growth of the cyst, we may pertinently ask, why was not the ostium of the right tube, which was nearer, closed by it and a right hydrosalpinx produced? The theory that the left hydrosalpinx was a developmental error, as was the right ovarian cyst, appears less open to objection, and here again, if it had existed for 15 years or more, it thoroughly explains the sterility.

CasE 4. There was double hydrosalpinx with recent peritonitis; menopause symptoms predominated. There was long-standing sterility. Advice had been sought soon after marriage, possibly for gonorrhœa, possibly for sterility. No history of vaginal discharge or of previous peritonitis could be obtained. The patient had "rheumatic fever" 12 years before operation; she had been married 24 years before operation. A reasonable explanation of the case seems to be that the tubes were abnormal for 28 years, causing sterility; at the menopause the hydrosalpinges became suddenly larger, and the peritonitis found at the operation was due to the pressure of the enlarging tubes.

Case 5. Previously considered at length. Faulty development appears to be the only explanation. There was practically no peritonitis. What there was may have been consequent on the diseased condition of the tubes, and may have helped to close the ostia.

CASs 6. Previously considered at length. If the right hydrosalpinx was secondary to the suppuration of the left tubo-ovarian cyst, a hydrosalpinx can form in about 14 days. I do not think in this case the walls of the hydrosalpinx could in so short a time have become as thin as they were.

CASE 7. Like case 4, double hydrosalpinx-unlike it, in being complicated by many changes in neighbouring organs. The existence of a cyst of Kobelt's tube is interesting as a definitely developmental error. BlandSutton has called attention to the frequent existence of a cyst of a duct of Kobelt or of a hydatid of Morgagni side by side with hydrosalpinx in cases of salpingitic closure of the ostia. The fibroids were small. The changes in one ovary, though definitely pathological, were not commensurate with the denseness of the adhesions. I think these were secondary to the hydrosalpinges, of which the right had grown at the expense of the mesosalpinx. The slight intermenstrual discharge may have been due to the hydrosalpinges. The patient had indulged in very frequent sexual intercourse with her husband, but denied any acute vaginal discharge, and sought advise because connection was so painful that it had to be limited to four times a week. A patient who gave such a history would not be likely to deny gonorrhoea if she had had it. In this case I think developmental error best accounts for the double hydrosalpinx.

CASE 8. Right pyosalpinx and left hydrosalpinx in a patient recently married; her symptoms date from marriage. Gonorrhœa was presumably the cause of the pyosalpinx. Was the right tube the first to which the gonococcus found access, and did the ostium of the left tube become closed by adhesive peritonitis, the remainder of the tube escaping purulent 
inflammation? (a similar sequence seems to have occurred in case 14) or was the hydrosalpinx an event in the course of a salpingitis?

CAse 9. Double hydrosalpinx, dense adhesions. The patient was an unmarried servant, aged $16 \frac{1}{2}$, in whom pregnancy was wrongly suspected. On examination three months prior to admission to hospital the hymen was found torn, and there was some vaginitis, and a tumour felt, which was thought to be the pregnant uterus. I do not know whether she had been previously examined. The vaginitis was not acute, and may have been secondary to the pelvic condition. Presuming it was gonorrhoeal, an endometritis may either have led to a consecutive double salpingitis, of which the hydrosalpinges were a stage, or may have spread through the uterine wall and set up a pelvic peritonitis which sealed the ostia of comparatively healthy tubes. The diagnosis of ovarian eyst made prior to operation would seem to show that the operator did not entertain the idea of gonorrhoeal infection. There were dense adhesions about the hydrosalpinges; the peritonitis may have been either the cause or effect of the tumours.

Case 10. Right hydrosalpinx, left tube and ovary inflamed. The patient, aged 43 , had been married 20 years, and had three children, the last 16 years previous to operation. The history points to gonorrhœa between the second and third confinements. Probably this infection set up inflammation in the pelvis, resulting in hydrosalpinx on the right side. The hydrosalpinx then would seem to have existed for 16 years, and may have given rise to some of the discharge complained of. She may have been re-infected, but there is no history pointing to anything like repeated attacks of pelvic inflammation. This may be a case, similar to those quoted by Dr. Cullingworth, in which pelvic inflammation, starting in the left tube, sealed the right abdominal ostium.

CASE 11. Large uterine fibroid, left hydrosalpinx in a patient, aged 50, married 24 years, with three children, the youngest 17 years old. After the birth of the last child she was in bed for six weeks with "bronchitis;" she "simply could not get strong." Was the left hydrosalpinx the result of perimetritis closing the abdominal ostium of the left tube, or was it due to actual inflammation of the tube (in either case being of 17 years' duration), or was it of recent formation due to closure of the ostium by peritonitis consequent on the growth of the uterine fibroid which led the patient to seek advice? The right ovary and tube were, I believe, healthy; there is no note to the contrary. I incline to the view that the hydrosalpinx followed the closing of the ostium of a healthy tube soon after child-birth.

Case 12. Large left multilocular cyst, right hydrosalpinx, the tube being converted into "several small cysts." Patient, aged 53, married, one child, aged 22, with history of three miscarriages (between three and four months of pregnancy), the last coincident with the menopause. The possibility presents itself that these were not miscarriages, but simply floodings at the menopause following periods of amenorrhoe. If they were miscarriages, the retroversion of the uterus may have had a bearing on the period of pregnancy, at which they are stated to have occurred. The right hydrosalpinx had caused no symptoms. Two hypotheses are tenable, either the hydrosalpinx was a developmental error, as was the ovarian cyst, or it was secondary to the latter, the abdominal ostium being closed by peritonitis. With regard to the second hypothesis, as in case 3 , the question arises, why was not the left ostium, which was nearer to the ovarian cyst, closed and a left hydrosalpinx formed? Did the cyst grow 
too fast to allow of the ostium closing? There was apparently no peritonitis observed in this case, so that I prefer the developmental theory. This patient was the oldest in my series.

CASE 13. Left ovarian cyst, right hydrosalpinx closely adherent to a cystic ovary. Patient, aged 40, married 23 years, one child, aged 21. This case shows a stage preceding that of tubo-ovarian cyst. I incline to the view that in this case the hydrosalpinx was a developmental error. Twelve years before operation the patient had twelve months' treatment for a "prolapsed and ulcerated womb." I endearoured, without success, to obtain a record of this from the hospital at which she attended. She wore a pessary, and had a good deal of vaginal discharge, possibly as a result. When seen at the London Hospital prior to operation there was slight prolapse of the anterior vaginal wall, and the uterus was in its normal position, though partially fixed, and behind it was a swelling " the size of a walnut;" this proved to be the right appendages. Possibly this may have been mistaken for the uterine body twelve years before.

CASE 14. Abdominal fotation, left ovarian cyst, right hydrosalpinx. The patient was fertile, and generally had excellent health. The left Fallopian tube and upper one-third of the uterus were in relation with the thrombosed placenta; the fotus, 15in. long, was in its membranes. The ovum would appear to have come from the right ovary and somehow reached the left tube, from which the embryo escaped into the abdominal cavity (unless it was a primary abdominal pregnancy). In this case there was twelve months for the right hydrosalpinx to develop, supposing its cause was closure of the abdominal ostium by peritonitis due to the extra uterine fotation. This, I think, is the simplest explanation. If it is the correct one, it supports Dr. Cullingworth's observations, already quoted.

CASE 15. Double hydrosalpinx in a sterile married woman, aged 42 , with symptoms, notably dyspareunia, for 15 years. A Bartholin's cyst (?) had been removed a few months prior to laparotomy. The only other history of note is of a stone in the bladder at 12 years of age. Possibly there was cystitis and local peritonitis at that age, causing the closure of the abdominal ostia. Possibly there was a developmental defect of the tubes. The occurrence of another retention cyst in this patient is noteworthy.

CAse 16. Right hydrosalpinx. To judge from the contents, chocolate coloured fluid containing red blood corpuscles and hæmin crystals, either hæmorrhage had taken place into a hydrosalpinx or a hæmatosalpinx was converted into a hydrosalpinx. The patient was aged 32 , married 13 years, had two children, the youngest four years old. At the second confinement there was " adherent placenta" and post-partum hæmorrhage, but speedy convalescence. There was one miscarriage, $2 \frac{1}{2}$ years previous to operation, followed by some endometritis for four months. She had been comparatively well since, except that the monthly losses were offensive, and for a year she had had pain. The tumour probably dates from after the miscarriage. The condition would seem to be a later stage of that seen in case 20 .

Case 17. Double hydrosalpinx in a woman, aged 31 , twice married. She had one miscarriage, followed by "endometritis" for four years. There seems no doubt that the hydrosalpinges were secondary to either perimetritis closing the abdominal ostia, or to salpingitis. One or both ostia were of necessity pervious prior to conception.

CAse 18. Right hydrosalpinx. Woman, aged 30 , married ten years, with no children, had two miscarriages, the last two years before operation. 
The right ovary was adherent to the hydrosalpinx. There was no history of repeated attacks of inflammation and no menorrhagia till the last five months, during which the patient was continually losing a coloured discharge. I think some pelvic peritonitis closed the ostium of a tube which was not inflamed. The left tube was apparently healthy; there is no note to the contrary.

Cass 19. Left hydrosalpinx. There is a history here of repeated attacks of inflammation and excessive monthly loss dating from a flooding (probably an incomplete miscarriage) four years before operation. The right appendages were normal. The left Fallopian tube was distended to the size of the little finger. In this case I think that probably the hydrosalpinx was a product of salpingitis. This was the smallest tumour in the series.

Cas a 20. Reported in the Obstetrical Society Transactions, Vol. xxxiii. Left hydrohæmatosalpinx in a single woman, of 34 . Hypertrophic elongation of the cervix was present. The thickness of the walls of the tube is unusual. In this case there was a six years' history of headache and bearing down pains. There is no history of peritonitis. There is no reason to doubt the patient's virginity. There was a developmental error in the cervix; a developmental error in the tube is a reasonable supposition. It is possible that septic infection got in through the cervix, which protruded at the vulva.

Resumé. Thus in nine cases the old view of hydrosalpinx as a stage in a salpingitis cannot be absolutely disproved, for the condition followed intrauterine pregnancy or gonorrhoea. In only one of these do I think the balance of evidence is definitely in favour of that view. In the other eight, I think, the evidence is in favour of a peritonitic closure of the ostium of a healthy tube in the way suggested by Dr. Cullingworth. In 10 cases my opinion is that the tumour was a retention cyst, a tumour sui generis, independent of neighbouring organs and due to faulty development. In case 14 the hydrosalpinx seems to have been due to peritonitic closure of the tube following extrauterine gestation.

Symptoms. The abstract of cases shows that uncomplicated cases of hydrosalpinx are rare. Some definitely are symptomless until some accident supervene, such as sudden eulargement of the tumours, or pelvic peritonitis, or growth of another tumour. Pain in the hypogastrium and vagina is by far the most prominent symptom. In some there is pain at the end of menstruation. Dyspareunia and dyschezia are fairly common, as is congestive dysmenorrhoea. Menorrhagia is exceptional, irregularity of menstruation is exceptional. Menstruation is commonly scanty in cases of hydrosalpinx; in fact, No. 19, where there were frequent attacks of pelvic inflammation, is almost the only marked exception to this rule. This single point would make one chary of accepting the view that hydrosalpinx is merely a stage of a salpingitis. 
Irregular and excessire menstruation is one of the most constant symptoms of salpingitis.

Concluding Remarks. That hydrosalpinx is a retention cyst most authors agree. That some cases are little more than a catarrhal salpingitis with an excessive amount of fluid retained, I am disposed to admit. That some are due to an cedematous condition in final stages of kidney disease is also probable. That some are due to peritonitic closure of the tube, otherwise healthy, seems to be true. But I believe that it may be found that many of those cases in which the appearance of the ostium is such as is commonly described as due to "salpingitic" closure of the tube * are cases of impervious ostia due to faulty development. It is in this class of case that Mr. BlandSutton had pointed out that a small pedunculated cyst is often present, whether due to a hydatid of Morgagni or Kobelt's tube he does not know. At least $I$ would insist that the clinical history in too large a proportion of my cases to be negligible is not the history of a salpingitis, is often marked by an absence of symptoms, and the symptoms which are present are such as are found in cases of maldevelopment, namely : sterility, pain, scanty menses, dysmenorrhœa, dyspareunia.

- See "On Closure of the Ostium in Inflammation and Allied Diseases of the Fallopian Tube," by A. Doran, Trans, Obstet. Soc., Vol. XXXI. The two conditions, perimetritic and salpingitic closure of the tube, are represented in Figs. 6 and 7 (p. 358). The original specimens are in the Pathological Collection of the Royal College of Surgeons, Nos. 4,504a and $b$. 